\title{
Research on the Impact of Digital Financial Inclusion on R\&D Innovation
}

\author{
Sun Mingyue ${ }^{1}$ a, Xu Jing ${ }^{2}$, Tang Haoyue ${ }^{3 c}, Z u$ Zishuai ${ }^{4 d}$ \\ ${ }^{1234}$ Shandong University of Science and Technology, Shandong, Jinan, 250031
}

\begin{abstract}
Based on the panel data of China's provinces from 2011 to 2019, this paper studies the impact of financial science and technology on scientific and technological innovation through fixed effect model. The empirical results show that scientific and technological innovation has a positive correlation with the Inclusive Financing index, indicating that the development of scientific and technological innovation will promote financial science and technology. The R\&D expenditure of industrial enterprises has a negative correlation with the Inclusive Financing Index, which shows that during the period of 2011-2019 in China, the research expenditure of enterprises does not affect financial technology, because the technology involved in financial technology has the characteristics of fast updating and iteration, cross-border and mixed operation, which is the superposition and integration of cutting-edge disruptive technologies such as big data, artificial intelligence and blockchain technology with traditional financial services and scenarios. Finally, some suggestions are put forward for the development of financial science and technology.
\end{abstract}

\section{Introduction}

On March 10, 2017, the Fifth Session of the Twelfth National People's Congress held a press conference. The Governor of the People's Bank of China Zhou Xiaochuan Zhou Xiaochuan said that the development of network technology, digital currency and blockchain and other new technologies will have an impact on the payment field . The People's Bank of China highly encourages and supports the development of financial technology. However, there is currently little domestic research on the impact of digital financial inclusion on technological development and innovation. Based on the above considerations, this article uses data from the National Bureau of Statistics of China from 2010 to 2019 to study the impact of financial technology on technological innovation in various provinces in China. influences.

The structure of this paper is as follows: The second part introduces the related literature that distinguishes the concept of technology finance and financial technology; the third part explains the source and preprocessing of the data in this paper, and also proposes the main theoretical model of this paper. The fourth part According to the theoretical model, the possible problems and solutions of the measurement estimation method and method are given. The fifth part is the empirical estimation result of the model, the sixth part is the endogenous problem and robustness test, and the seventh part is the basis of the previous analysis The main conclusions and relevant policy recommendations are drawn from the above.

\section{Literature review}

\subsection{The concept and difference between financial technology and technology finance}

Regarding the definition of the concept of financial technology, Lu Minfeng (2019) believes that the concept of domestic financial technology is an extension of the concept of Internet finance [1]. Internet finance is a transitional concept of a specific period and specific content. It is based on the "Guiding Opinions on Promoting the Healthy Development of Internet Finance" jointly issued by ten ministries and commissions including the People's Bank of China. After more than three years of special rectification of Internet finance, there are now only temporary deposits of Internet payment, Internet small loans and online lending in seven subdivisions, including financing and online lending. These three formats are completely included in the traditional financial formats. The Internet as a tool for definancialization is very clear, and with the development of mobile Internet technology, big data, blockchain, artificial intelligence, Internet of Things, and cloud computing And so on, have poured into the financial industry and served it, which together constitute the technological means for financial services, that is, financial technology. Therefore, financial technology is a collection of technologies, not finance. Finance is only the main body or goal of technology services. Deng 
Mingjian (2019) believes that financial technology is the application of advanced and new scientific and technological achievements to the financial field or category. It is a process of the integration and development of the financial industry and the technology community, because this process has a profound impact on the financial industry. Financial technology is constantly improving and developing over time, so its impact on the financial field is continuous and comprehensive, and it plays an important role in the business process, product design, organizational system, etc. of the financial industry. At present, the innovative development of the financial industry has been continuously empowered and upgraded by financial technology [2]. Li Juan (2019) believes that financial technology is mainly reflected in the deep integration of finance and technology, and these new technologies are widely used in various fields of traditional finance. The scope of the concept of financial technology is larger than that of the concept of Internet finance, and it also has special risk characteristics, and its influence on the financial industry will continue to be highlighted ${ }^{[3]}$.

Regarding the definition of technology finance, Jiang Ying (2018) believes that technology finance refers to the process by which various financial investment institutions invest in technology-based small and medium-sized enterprises with the help of various investment tools to support the development of technology-based enterprises. Investment entities are mainly various investment institutions, including commercial banks, capital markets, financial institutions, etc., and investment tools are not just commercial bank loans. Stocks, bonds, etc. are all within the scope. From the perspective of service targets, the main Refers to small and medium technology companies. The vigorous development of science and technology finance is crucial to the transformation and upgrading of my country's economic structure and the drive for industrial innovation ${ }^{[4]}$. Zhang Meng (2016) believes that technology finance is mainly to improve the innovation and creativity of small and medium-sized technology companies, and effectively solve the financing difficulties and expensive financing problems of small and medium-sized technology companies. Using financial means to solve the financial format of the development of small and medium-sized technology companies is the integration of "technology + finance". Through this integration, it promotes the innovative development of small and medium-sized technology companies, solves the urgently needed funding difficulties, and stimulates the development of technology companies. Intrinsic motivation provides a powerful driving force for the transformation and upgrading of the social and economic structure . Lu Minfeng and Huang Baihui (2019) believe that technology finance is a branch of the financial industry, which refers to the general term for a package of financial services provided by financial institutions to technological innovation companies. Technology finance is finance, and technology is the object of financial services. Technology finance covers a wide range, including direct financing for technology companies, indirect financing by commercial banks, insurance, and so on. Of course, the financial business used in technology companies can also be applied to other companies, but in terms of product design, risk identification, etc., technology finance appears to reflect the characteristics of technology companies ${ }^{[1]}$.

\subsection{Current status of domestic research}

Domestic scholars' research on financial technology and inclusive finance started late compared to foreign countries. With the continuous innovation of Internet technology and the continuous development of the domestic economy, research on financial technology is becoming more and more popular. The combination of inclusive finance and financial technology has become the focus of current financial research. In recent years, domestic research on financial technology and inclusive finance has mostly focused on the connotation and development history of financial technology and inclusive finance, the application of financial technology in inclusive finance, and the supervision, prevention and control of financial risks. In terms of the development process of financial technology, Zhu Li and Hua Wenjun (2017) briefly introduced the development process of financial technology into three stages, and it is currently transitioning from the second stage to the third stage.Regarding the application of financial technology in inclusive finance, Yao Yuan (2017) proposed to broaden the development path of financial technology in inclusive finance by strengthening the protection of consumer rights, strengthening financial technology supervision, and creating a benign policy environment. Technology has become the foundation and continuous driving force for promoting the development of inclusive finance. In terms of financial technology promoting the development and transformation of financial institutions, Lin Yuan (2018) pointed out that the development of financial technology has greatly impacted traditional banks. Commercial banks should give full play to their advantages, actively embrace financial technology companies, and realize the integration of traditional finance and financial technology. Combine. In terms of risk control, Lu Dengqiang (2018) proposed to actively promote the transformation of inclusive financial services from offline to online through financial technology, so that most people can enjoy higher-quality, safe and efficient financial services. Shen Yanbing (2018) suggested that in order to promote the healthy development of inclusive finance, GS Bank should not use financial technology to develop inclusive finance strategy research to continuously improve the development environment and development methods of my country's inclusive finance, and strengthen the supervision and prevention of financial risks. In terms of the connotation of inclusive finance, Wu Xiaoling (2015) believes that the connotation of inclusive finance is that financial institutions provide financial services at reasonable prices, treat all customers equally, and meet the financial service needs of all customers. Li Guihua (2018) proposed that the credit system is the foundation 
of inclusive finance, and financial technology is a necessary means for the development of inclusive finance.In terms of the development direction of inclusive finance, Zhao Meng (2018) pointed out that banks need to increase policy support for inclusive finance in the future, focus on the future development of inclusive finance business in rural areas, and continue to promote the popularization of inclusive finance in rural areas. . In terms of financial services in rural areas, Lin Hongshan (2014) pointed out that financial institutions are more willing to provide services to large enterprises and large customers, thus ignoring the financial needs of small and micro enterprises, especially individual industrial and commercial households, and that financial needs in rural areas are more difficult to meet. Wei Wenyue (2016) conducted a comprehensive analysis of the development status of China's rural inclusive finance, summarized the reasons for the backwardness of rural inclusive finance, and put forward suggestions for establishing a rural inclusive finance system. In terms of the development status, risk characteristics and management research of inclusive finance, $\mathrm{Lu}$ Minfeng and $\mathrm{Xu}$ Bohuan (2019) proposed that inclusive finance is of great significance to my country's economic construction and social stability, and the development of inclusive finance should be vigorously supported, and at the same time, financial technology and risk should be adhered to combine management.

Based on this, research on the impact of digital financial inclusion on $R \& D$ innovation

\section{Data and theoretical model}

\subsection{Data source}

This article uses data from the National Bureau of Statistics of China from 2010 to 2019 . The data counts the digital financial inclusion index, the consumption level of urban residents, the R\&D expenditure of industrial enterprises above designated size $(10,000$ yuan), and the number of domestic patent applications granted (items) , Technology market turnover (100 million yuan), local financial science and technology expenditure (100 million yuan), regional GDP (100 million yuan), Internet broadband access ports $(10,000)$, etc. However, a small part of the data is missing. Therefore, the data needs to be preprocessed.

\subsection{Methods of processing missing values}

Mean imputation. The attributes of the data are divided into fixed-distance type and non-fixed-distance type. If the missing value is of fixed-range type, the average value of the existing value of the attribute is used to interpolate the missing value; if the missing value is of non-ranged type, the mode of the attribute is used according to the principle of mode in statistics. (Ie the most frequently occurring value) to fill in missing values.

\subsection{Theoretical model}

This paper conducts a regression study on the impact of financial technology on technological innovation. $f$ int ech $=\alpha_{k}+\alpha_{t}+\beta_{1}$ funds $_{i j t}+\beta_{2}$ patent $_{i j k t}+\beta_{3}$ turnover $_{i j k t}+X_{\mathrm{i}}+e_{i j k t}$

\section{Measurement model and estimation method}

\subsection{Benchmark model}

In order to estimate the impact of China's financial technology on technological innovation, this article adopts a benchmark measurement model, in which ftechnology is an explained variable related to China's financial technology. In this article, we mainly study the inclusive financial index (ifindex). $\alpha_{k}$ and $\alpha_{t}$ are individual fixed effects and time fixed effects, funds ${ }^{i j t}$ representative $\mathrm{R} \& \mathrm{D}$ expenses of industrial enterprises above designated size (ten thousand yuan),

patent $_{i j k t}$ represents the number of authorized domestic patent applications (items),

turnover ${ }_{i j k t}$ representative technology market turnover (100 million yuan), $X_{\text {i Control variables at the provincial level, }}$ mainly including: consumption level of urban residents in each province (Consumption), local fiscal science and technology expenditure (100 million yuan) (expenditure), regional gross product (100 million yuan) (GDP), Internet broadband access ports (Ten thousand) (access). The following are the selected variables.

Table 1 Variable

\begin{tabular}{c|l}
\hline Explained variable & Digital Financial Inclusion Index \\
\hline \multirow{4}{*}{ Explanatory variables } & $\begin{array}{l}\text { R\&D expenditure of industrial } \\
\text { enterprises above designated size } \\
\text { (ten thousand yuan) }\end{array}$ \\
\cline { 2 - 2 } Control variable & $\begin{array}{l}\text { Number of domestic patent } \\
\text { applications granted (items) }\end{array}$ \\
\cline { 2 - 2 } & $\begin{array}{l}\text { Technology market turnover (100 } \\
\text { million yuan) }\end{array}$ \\
\cline { 2 - 2 } & $\begin{array}{l}\text { Consumption level of urban } \\
\text { residents }\end{array}$ \\
\cline { 2 - 2 } & $\begin{array}{l}\text { Local financial expenditure on } \\
\text { science and technology (100 } \\
\text { million yuan) }\end{array}$ \\
\cline { 2 - 2 } & $\begin{array}{l}\text { Gross Regional Product (100 } \\
\text { million yuan) }\end{array}$ \\
\cline { 2 - 2 } & $\begin{array}{l}\text { Internet broadband access ports } \\
\text { (ten thousand) }\end{array}$ \\
\hline
\end{tabular}

The selection of the above variables is mainly based on the following considerations:

1. Refers to the use of various technological means to innovate the products and services provided by the traditional financial industry to improve efficiency and 
effectively reduce operating costs. According to the definition of the Financial Stability Board (FSB), financial technology mainly refers to emerging business models that are driven by emerging cutting-edge technologies such as big data, blockchain, cloud computing, and artificial intelligence, which have a significant impact on the financial market and the supply of financial services. , New technology applications, new products and services, etc.

(1) Inclusive finance index refers to inclusive finance, which refers to the provision of appropriate and effective financial services at affordable costs for all social classes and groups in need of financial services based on the requirements of equal opportunities and the principle of business sustainability. As more and more science and technology serve the financial field, it can more effectively meet the financial needs of all classes and groups of society.

2 .Scientific and technological innovation refers to specific activities used by industrial enterprises in technological innovation and technological development. Including direct expenditures for corporate research and development subject activities, as well as all expenditures indirectly used for research and development activities.

(1) The R\&D expenditure of an industrial enterprise measures the degree of importance it attaches to scientific and technological innovation. Intuitively, the more R\&D expenses of an industrial enterprise, the greater the possibility of the enterprise producing scientific and technological innovation results.

(2) The number of domestic patent applications granted (items) measures the theoretical output of scientific and technological innovation. Intuitively, the more domestic patent applications (items) are granted, the more likely it is to serve the actual application field, thereby improving the ability and level of technological innovation.

(3) The technological market turnover measures the actual output of technological innovation. Intuitively, the more technological market turnover, the more technologically-led trade, and the higher the ability of technological innovation to serve practical applications.

\subsection{Estimation method}

In the selection of fixed effects and random effects models, this article has the following considerations. Intuitively, the data used in this article comes from 31 provinces, cities and autonomous regions in China, which almost represent the entire research sample. Within this sample interval, the differences in each province are Qualitative indicators can be regarded as constant; on the other hand, the random effects model sets the effect of each item as a part of the interference, and requires that the explanatory variable is not related to the individual effect. At the same time, the Hausman test is used to reject at the significance level of 0.01 That assumption. Therefore, this article uses a panel regression model with fixed effects.

\subsection{Problems in the model and solutions}

(1) Endogenous problems

This article studies the impact of China's financial technology on technological innovation. The endogenousness of the model mainly comes from omitted variables, reverse causality, and selective bias. Regarding the omitted variables, this article adds the control variables of the consumption level of urban residents in each province (Consumption), local fiscal science and technology expenditure (100 million yuan) (expenditure), regional GDP (100 million yuan) (GDP), and Internet broadband access ports ( Ten thousand (access); for the problem of reverse causality, the endogenous reason is: On the one hand, financial technology serves the finance of science and technology and generates demand, which will stimulate the development of technological innovation; on the other hand, the development of technological innovation It will also accelerate the speed at which technology serves the financial sector. This article uses the instrumental variable method to test the endogeneity problem in the sixth part.

(2) Robustness issues

When considering the impact of financial technology on technological innovation, we must consider regional heterogeneity, such as the central region, the western region, and the eastern region. In the sixth part of this article, the robustness is tested by sub-sample regression.

\section{Empirical analysis results}

This paper uses the data indicators of various provinces in China from 2011 to 2019 to regress scientific and technological innovation through a fixed-effect model. Table 2 reports the results of the regression. Among them, the regression result of (1) is only the regression result of adding the core variables of industrial enterprises above designated size R\&D expenditure (ten thousand yuan), domestic patent application authorization volume (item), technology market turnover (100 million yuan), and (2) to (4) Column is the addition of control variables, in order of urban residents' consumption level, local fiscal expenditure on science and technology (100 million yuan), regional GDP (100 million yuan), and the result of regression. Column (5) considers all the above core variables And the regression results after the control variables.

Table 2 Regression results of the impact of financial technology on technological innovation

\begin{tabular}{|c|c|c|c|c|c|}
\hline & $\begin{array}{c}\text { (1) } \\
\text { fintech }\end{array}$ & $\begin{array}{c}(2) \\
\text { fintech }\end{array}$ & $\begin{array}{c}(3) \\
\text { fintech }\end{array}$ & $\begin{array}{c}(4) \\
\text { fintech }\end{array}$ & $\begin{array}{c}(5) \\
\text { fintech }\end{array}$ \\
\hline funds & $\begin{array}{c}0.00000273 \\
(0.97)\end{array}$ & $\begin{array}{c}-0.00000397 \\
(-1.78)\end{array}$ & $\begin{array}{c}-0.00000432 \\
(-6.28)\end{array}$ & $\begin{array}{c}-0.0000211 * * * \\
(-1.90)\end{array}$ & $\begin{array}{c}-0.0000134^{* *} \\
(-2.80)\end{array}$ \\
\hline
\end{tabular}




\begin{tabular}{|c|c|c|c|c|c|}
\hline patent & $\begin{array}{c}0.000164 \\
(0.98)\end{array}$ & $\begin{array}{c}0.000157 \\
(1.21)\end{array}$ & $\begin{array}{c}0.0000931 \\
(0.61)\end{array}$ & $\begin{array}{c}0.0000580 \\
(0.40)\end{array}$ & $\begin{array}{c}0.000361 * \\
\quad(2.21)\end{array}$ \\
\hline turnover & $\begin{array}{c}0.0352 * * * \\
(4.55)\end{array}$ & $\begin{array}{c}-0.0271 * * * \\
(-3.60)\end{array}$ & $\begin{array}{c}-0.0293 * * * \\
(-3.65)\end{array}$ & $\begin{array}{c}-0.0389 * * * \\
(-5.09)\end{array}$ & $\begin{array}{c}-0.0292 * \\
(-2.28)\end{array}$ \\
\hline consumption & & $\begin{array}{c}0.00822 * * * \\
(13.61)\end{array}$ & $\begin{array}{c}0.00811 * * * \\
(13.09)\end{array}$ & $\begin{array}{c}0.00854 * * * \\
(14.66)\end{array}$ & $\begin{array}{c}0.0104 * * * \\
(10.64)\end{array}$ \\
\hline expenditure & & & $\begin{array}{c}0.545 \\
(0.78)\end{array}$ & $\begin{array}{c}0.0178 \\
(0.27)\end{array}$ & $\begin{array}{l}-0.113 \\
(-1.51)\end{array}$ \\
\hline GDP & & & & $\begin{array}{c}0.00422 * * * \\
(6.43)\end{array}$ & $\begin{array}{c}0.00159 \\
(0.90)\end{array}$ \\
\hline access & & & & & $\begin{array}{c}0.0346^{* * *} \\
(5.60)\end{array}$ \\
\hline _cons & $\begin{array}{c}173.6^{* * *} \\
(26.67)\end{array}$ & $\begin{array}{c}7.653 \\
(0.58)\end{array}$ & $\begin{array}{l}9.162 \\
(0.69)\end{array}$ & $\begin{array}{c}-35.16^{*} \\
(-2.47)\end{array}$ & $\begin{array}{c}-126.2 * * * \\
(-6.70)\end{array}$ \\
\hline $\mathrm{N}$ & 279 & 279 & 279 & 279 & 221 \\
\hline
\end{tabular}

From the regression results, we can find that from the perspective of explanatory variables, domestic patent application licensing volume and technology market turnover are positively correlated to the Inclusive Financing index, indicating that the development of scientific and technological innovation will promote financial technology; The R\&D funding of industrial enterprises is positively correlated with the Inclusive Financing index, indicating that during the period of 2011-2019 in China, corporate research funding does not apply to financial science and technology, because the technology involved in financial science and technology has the characteristics of fast updating and iteration, cross-border and mixed industries, and is the superposition and integration of cutting-edge disruptive technologies such as big data, artificial intelligence and block chain technology with traditional financial businesses and scenarios ${ }^{[5]}$. It mainly includes four core parts: big data finance, artificial intelligence finance, block chain finance and quantitative finance, and these technologies have only arisen in recent years. From the perspective of control variables, the addition of local financial expenditure on science and technology (RMB100 million), regional GDP (RMB100 million) and Internet broadband access ports $(10,000)$ has a positive correlation with the Inclusive Financing index, which is consistent with the original intention of this paper to add covariates.

\section{Endogenity and robustness test}

\subsection{Endogenous problems}

This article uses two ways to control endogenity. One is to use control variables, such as local fiscal expenditures on science and technology (100 million yuan), regional GDP (100 million yuan), and Internet broadband access ports $(10,000)$. Solve the problem of missing variables; for the endogeneity of the reverse causality perspective, this article considers using the instrumental variable method to solve the problem of endogeneity. Since the rise of fintech relies on big data finance, artificial intelligence finance, blockchain finance and quantitative finance, and these technologies have emerged in recent years, the original technological innovations carried out by enterprises hardly affect fintech, and are also reflected in the return results. Can be verified. Therefore, the sales income of new products of industrial enterprises above designated size (ten thousand yuan) is selected as the instrumental variable, which also presents relevance to technological innovation.

Table 3 Instrumental Variable Method

\begin{tabular}{cc}
\hline & $(1)$ \\
fintech \\
\hline funds & $-0.00000868^{* *}$ \\
& $(-2.88)$ \\
patent & $0.00674^{* * *}$ \\
& $(16.59)$ \\
turnover & -0.0224 \\
& $(-0.54)$ \\
consumption & $0.00674^{* * *}$ \\
& $(16.59)$ \\
expenditure & -0.0224 \\
& $(-0.54)$ \\
GDP & $-0.00252^{* *}$ \\
& $(-3.06)$ \\
access & $0.0613 * * *$ \\
& $(13.12)$ \\
cons & 6.306 \\
& $(0.59)$ \\
$\mathrm{N}$ & 278 \\
\hline
\end{tabular}

\subsection{Stability test}

Using sub-samples for testing, select provinces in China that are in the top $80 \%$ of the $R \& D$ expenditures of industrial enterprises (ten thousand yuan), domestic patent applications (items), and technology market turnover (100 million yuan) for fixed effects regression.

Table 4 The fixed-effect model of the impact of financial technology on technological innovation after the robustness test

\begin{tabular}{|c|c|}
\hline & $\begin{array}{c}\text { (1) } \\
\text { fintech }\end{array}$ \\
\hline funds & $\begin{array}{c}-0.0000134 * * \\
(-2.80)\end{array}$ \\
\hline patent & $\begin{array}{c}0.000361 * \\
(2.21)\end{array}$ \\
\hline turnover & $\begin{array}{l}-0.0292 * \\
(-2.28)\end{array}$ \\
\hline consumption & $\begin{array}{c}0.0104 * * * \\
(10.64)\end{array}$ \\
\hline
\end{tabular}




\begin{tabular}{cc} 
expenditure & -0.113 \\
& $(-1.51)$ \\
GDP & 0.00159 \\
& $(0.90)$ \\
access & $0.0346^{* * *}$ \\
& $(5.60)$ \\
cons & $-126.2^{* * *}$ \\
& $(-6.70)$ \\
$\mathrm{N}$ & 221 \\
\hline
\end{tabular}

\section{Conclusions and policy recommendations}

It can be concluded from the empirical results that most of the financial technology has a positive correlation with technological innovation, which is obviously beneficial. The country should accelerate the development of top-level design of financial technology, accelerate the reform of the traditional financial system, and master the international voice.

\section{References}

1. Lu Minfeng, Huang Baihui. The next stop of Internet finance: financial technology $[\mathrm{J}]$. Enterprise Research, 2019 (3): 16-18.

2. Deng Mingjian. On the development and trend of financial technology $[\mathrm{J}]$. Beijing Financial Review, 2019(1): 17-24.

3. Li Juan, Li Jianying. Regional differences in the development of financial technology in China $[\mathrm{J}]$. Inner Mongolia Science and Technology and Economy, 2019(5): 32-33.

4. Jiang Ying, Yang Hongbo. Analysis of the status quo of the development of science and technology finance in my country and countermeasures[J]. Journal of Shanghai Lixin University of Accounting and Finance, 2018(1): 83-94.

5. Henderson, J.V., A. Kuncoro and M. Turner, 1995, Industrial Development in Cities, Journal of Political Economy, 103, 1067- 1085. 